\title{
The Cost Structure of Water Utilities in Switzerland
}

Andrea Baranzini and Anne-Kathrin Faust

Cahier : N ${ }^{\circ}$ HES-SO/HEG-GE/C--10/5/1--CH

2010 


\title{
The Cost Structure of Water Utilities in Switzerland
}

\author{
Andrea Baranzini and Anne-Kathrin Faust
}

Working Paper

This version: April 2009

\begin{abstract}
This paper estimates a translog cost function for Swiss water utilities. From the cost function, we are able to estimate measures of marginal costs as well as economies of production density, customer density and scale, which are important determinants in water policies, such as planning and water tariffs. In order to explore the determinants of water supply costs, their structure and composition, the translog cost function does not only include output and input prices, but further integrates environmental factors such as the proportion of households among customers and water losses. We find moderate returns to production density, which decrease with the size of the utility.
\end{abstract}

\section{Keywords}

Water utilities, cost function, translog cost function, returns to scale.

\section{Acknowledgements}

We thank the Swiss Gas and Water Industry Association (SGWA) for providing the data. Our research is financed by the Network of competencies in economics and management of the University of Applied Sciences Western Switzerland (HES SO). The findings, interpretations, conclusions and any remaining errors are the authors' own. This paper was accepted for presentation at the $2^{\text {nd }}$ International Conference on Water Economics, Statistics and Finance in Alexandroupolis, 3-5 July 2009. 


\title{
The Cost Structure of Water Utilities in Switzerland
}

\author{
- Andrea BARANZINI", Anne-Kathrin FAUST ${ }^{*}$ \\ "Haute École de Gestion de Genève - Geneva School of Business Administration (HEG \\ Ge), University of Applied Sciences Western Switzerland (HES SO), Campus de Battelle, \\ Bâtiment F, 7 route de Drize, $\mathrm{CH}$ - 1227 Carouge-Genève, Switzerland, \\ andrea.baranzini@hesge.ch, anne-kathrin.faust@hesge.ch.
}

\begin{abstract}
This paper estimates a translog cost function for Swiss water utilities. From the cost function, we are able to estimate measures of marginal costs as well as economies of production density, customer density and scale, which are important determinants in water policies, such as planning and water tariffs. In order to explore the determinants of water supply costs, their structure and composition, the translog cost function does not only include output and input prices, but further integrates environmental factors such as the proportion of households among customers and water losses. We find moderate returns to production density, which decrease with the size of the utility.
\end{abstract}

Key words: water utilities, cost function, translog cost function, returns to scale.

Acknowledgements: We thank the Swiss Gas and Water Industry Association (SGWA) for providing the data. Our research is financed by the Network of competencies in economics and management of the University of Applied Sciences Western Switzerland (HES SO). The findings, interpretations, conclusions and any remaining errors are the authors' own. This paper was accepted for presentation at the $2^{\text {nd }}$ International Conference on Water Economics, Statistics and Finance in Alexandroupolis, 3-5 July 2009.

\section{Introduction and context}

Switzerland possesses a relatively large water endowment and is classified as a high water availability country. Although the size of the country is relatively small (about $41^{\prime} 000 \mathrm{Km}^{2}$ ) and the population is of about 7.5 millions only, Swiss regions and thus water utilities face very diverse conditions and constraints. In particular, since about $70 \%$ of the inhabitants live in urban areas, population density is relatively high in the metropolitan areas, whereas it is quite low in mountainous regions, which represent about half of the Swiss territory. Moreover, climatic, topographic and water conditions are quite different from one region to the other. Switzerland is a federal state and thus the responsibility of water supply is divided between the federal, 
cantonal and municipal levels (for a detailed discussion of water institutions in Switzerland, see Luís-Manso, 2005). The main responsibility of the Confederation is to set the legal framework for water protection and the drinking water quality standards, with a limited role in the financing of infrastructures within the context of water protection. Contrary to other countries, except for quality standards, no central water regulator exists in Switzerland, although there is a Price Supervisor who can also judge about water price levels. Drinking water provision and control are thus mostly within the competence of the Cantons, which however generally delegate those responsibilities to various degrees to the municipalities - from a very limited delegation as in the case of the Canton of Geneva, to a relatively complete delegation, as in the case of the Canton of Valais. In turn, municipalities can choose different management and organization structures. In particular, smaller municipalities favour sub-contracting of infrastructure maintenance and/or increasingly tend to group into inter-municipal associations, while bigger municipalities have a specific water service or an industrial service grouping water distribution with wastewater treatment, electricity and natural gas supply.

Summarizing, we can highlight that the drinking water market in Switzerland is highly segmented and characterized by a very large number of water utilities (about 3000 ) acting as local monopolies very often controlled by the municipalities. In addition to quite different management structures, water utilities are confronted with very diverse environmental conditions, such as costumer density, topography and water sources.

Although there seems to be a general consensus that the Swiss water market has to be preserved from the liberalization pressures which are presently acting in other network industries, there is nevertheless a raising concern about their performance (e.g. see Kilchman, 2003) and the small size of many of the utilities.

Albeit its unique features make Switzerland an interesting case of study, it has been given little attention so far. Baranzini (1996) analyses the cost structure of Swiss sewerage utilities, while Farsi and Filippini (2009) estimate the cost-efficiency in Swiss multi-utilities. On the contrary, there is considerable literature on the analysis of the cost structure of water distribution in other countries, such as the United Kingdom. Recent applications include Bottasso and Conti (2008) and Saal and Parker (2001). Garcia and Thomas (2001) analyse the French water distribution sector, while Fabri and Fraquelli (2000) concentrate on Italy. Torres and Morrison (2006) focus on the United States and Nauges and van den Berg (2008) study water supply and the sewerage sector in Brazil, Moldova, Romania and Vietnam.

The main objective of this paper is to contribute to the current debate on the structure of the Swiss water distribution market by analysing the cost elements of the Swiss water distribution sector. Econometric techniques enable us to fully characterize the water "production" process. We estimate a translog cost function for Swiss water utilities and from it we measure marginal costs as well as economies of customer density and scale, which are important determinants of water policies, such as production planning and water tariffs. This paper is part of an on-going research project on the analysis of the costs and the measurement of the efficiency of Swiss drinking water utilities (see a companion paper by Baranzini, Faust and Maradan, 2008).

The structure of the paper is the following. Section 2 discusses the theoretical approach and its empirical implementation. Section 3 defines the variables and presents the descriptive statistics of the sample. Section 4 discusses the results, while 
section 5 concludes and highlights future research questions analysed within our project.

\section{Model specification and empirical implementation}

In this paper, we estimate a variable cost function. We prefer it to a total cost function, because the latter supposes that the producers are at their long term equilibrium and that they use their production factors at the level minimising total cost. In the case of the water utilities, such an assumption is relatively strong, in particular with regard to their capital stock, which may not be at its optimal level for two main reasons. Firstly, modifications in the capital stock are relatively costly and thus the size of the main water utilities infrastructures is typically based on demographic and economic previsions, which can be wrong. Secondly, water utilities have to respond to all the demand, and thus in order to account for seasonal and unexpected demand variations (e.g. in case of fire), they typically dispose of excess capacities. For those reasons, the capital stock of the water utilities can be considered fixed in the short term and only adjusting partially with respect to its long term equilibrium. In this latter case however, the total cost function is not suitable and a variable cost function should be estimated.

The traditional cost function only includes output, price and quasi-fixed input variables, and thus does not account for the environment in which the firms operate. However, environmental variables can have a substantial impact on the costs and it is therefore important to include them, especially in very heterogeneous markets. Indeed, as already mentioned, water utilities in Switzerland face very different production conditions. That is why some environmental factors and a network quality measure are included into the analysis.

To estimate the variable cost function, a functional form is needed. In this paper, the analysis is based on a one output, three input translog function, including three environmental and one quality related factor, which takes the following form:

$$
\begin{aligned}
& \ln \left(\frac{W E}{p N A}\right)=\alpha+\alpha_{u}+\beta_{r} \ln Y+\beta_{n z} \ln \left(\frac{p z}{p W A}\right)+\beta_{p \varepsilon} \ln \left(\frac{p E}{p W A}\right)+\beta_{s \infty p} \ln C A P+
\end{aligned}
$$

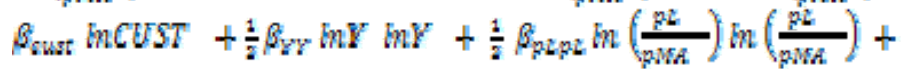

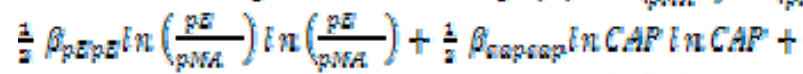

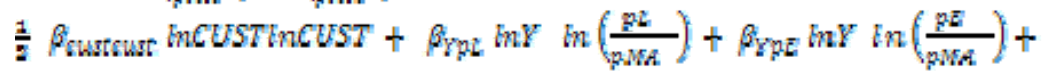

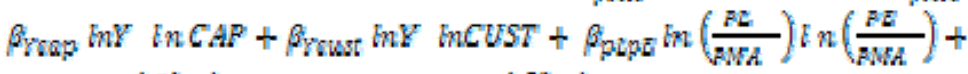

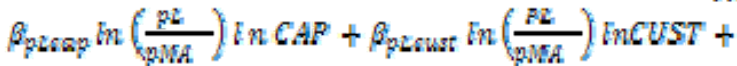

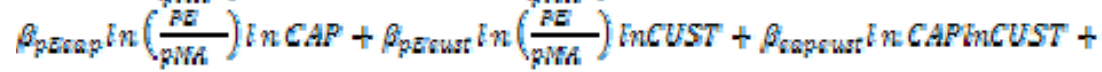

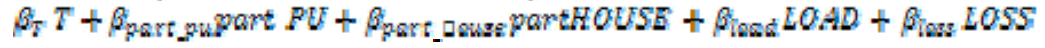

where $\mathrm{VC}$ are the variable costs, $\mathrm{y}$ is the quantity of water delivered; $\mathrm{P}_{\mathrm{L}}$ the labour price; $\mathrm{P}_{\mathrm{E}}$ the energy price; $\mathrm{P}_{\mathrm{MA}}$ the price of materials; CAP the stock of capital; CUST the number of customers and $\mathrm{T}$ a time trend. partPU is the proportion of water that is pumped; partHOUSE is the proportion of water delivered to households; LOAD the load factor and LOSS are network losses, while $\alpha$ is the constant and $\alpha_{u}$ a utility specific fixed effect. The costs and factor prices are normalized by the price of 
materials in order to guarantee homogeneity in input prices and $\beta_{\mathrm{jn}}=\beta_{\mathrm{nj}}$ imposes symmetry.

In order to improve the efficiency of the estimation of the parameters of the variable cost function, we estimate a system including the variable cost function (1) and the cost shares. Applying Shephard's lemma, cost shares can be written as:

$$
\begin{aligned}
& s_{L}=\beta_{L}+\beta_{p q L} \ln Y+\beta_{p L z L} \ln \left(\frac{p L}{p N A}\right)+\beta_{p q L} \ln \left(\frac{P E}{P N A}\right) \\
& +\beta_{\text {pzeap }} \text { in CAP }+\beta_{\text {nzeust }} \text { inCUST }
\end{aligned}
$$

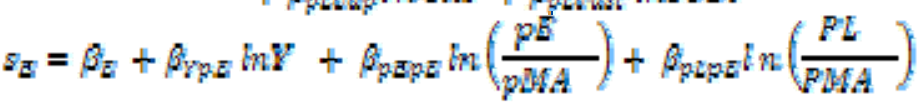

$$
\begin{aligned}
& +\beta_{\text {nesap }} i n C A P+\beta_{\text {nesust }} \text { inCUST }
\end{aligned}
$$

The cost share equation for material and other costs is not included in the estimated system to avoid singularity problems. Own-price elasticities are defined as $\varepsilon_{\mathrm{ii}}=\left[\left(\beta_{\mathrm{ii}}+\mathrm{s}_{\mathrm{i}}\left(\mathrm{s}_{\mathrm{i}}-1\right)\right] / \mathrm{s}_{\mathrm{i}}\right.$, cross-price elasticities are $\varepsilon_{\mathrm{ij}}=\left(\beta_{\mathrm{ij}}+\mathrm{s}_{\mathrm{i}} \mathrm{s}_{\mathrm{j}}\right) / \mathrm{s}_{\mathrm{i}}$ and Morishima elasticities of substitution can be calculated as $\sigma \mathrm{ij}=\varepsilon_{\mathrm{ii}}-\varepsilon_{\mathrm{ij}}$. From the estimation of the system of the cost function (1) and the cost shares (2), we can evaluate the returns to production density, to customer density and to scale. Returns to production density measure how the costs vary if the output is increased, while the number of customers and network length is kept constant. They are defined as:

$$
\mathrm{RPD}=\frac{1}{\frac{\sin \mathrm{V} C}{\ln \mathrm{Y}}}
$$

The variation of costs after an increase in both output and customers is quantified by economies of customer density:

$$
\mathrm{RCD}=\frac{1}{\frac{\varepsilon \ln W \mathrm{C}}{\varepsilon \ln \mathrm{F}}+\frac{\varepsilon \ln \mathrm{WC}}{\varepsilon \ln \mathrm{CUST}}}
$$

Finally, returns to scale measure how costs vary after an increase in output, customers and network length. They give important indications on market structure and on the consequences of concentration in a given market:

$$
\mathrm{RTS}=\frac{1-\frac{\varepsilon \ln \mathrm{VC}}{\delta \ln \mathrm{CAP}}}{\frac{\delta \ln \mathrm{VC}}{\delta \ln \mathrm{Y}}+\frac{\delta \ln \mathrm{CV}}{\delta \ln \mathrm{CUST}}}
$$

\section{The data}

This study uses a database of the Swiss Gas and Water Industry Association (SGWA), which originally contains information on about 330 water utilities, over the period 2000 to 2006 . It should be emphasized that the database does only include about $10 \%$ of the about 3'000 existing Swiss water utilities. However, the utilities included in the survey accounted for approximately $55 \%$ of the water distributed in Switzerland in 2005. This implies that larger water utilities are overrepresented in the database. We should nonetheless highlight that, as shown in Table 1, the utilities included in the database still differ widely in terms of size, structure, water resources, geological characteristics of the distribution area, production processes and customer demand and are situated all across Switzerland. As already mentioned, most of them 
are public companies owned by the municipalities, some acting also as electricity and gas distributors.

Since in the original SWGA database there are a lot of missing values in 2000 and 2001, especially those necessary in order to measure labour cost, we decided to exclude the observations from those years from our sample. After eliminating some aberrant values that were clearly invalid, as well as outliers based on a Welsh distance criteria, our final sample is an unbalanced panel containing data on 104 water distribution utilities and a total of 340 observations over the years 2002 to 2006 .

The output is measured as the total quantity of water supplied to the customers in thousands of cubic meters. Variable costs are calculated by summing labour costs, energy costs, material expenses and "other expenses". The price of labour is defined as total labour costs divided by the number of employees. Unfortunately, the database contains only the number of employees working part time and full time, but no information is given on the full time equivalent of people employed. We thus calculate the full time equivalent assuming that part time employees are working halftime on average. The energy price is computed as energy expenses divided by energy consumption. The third input is materials. As in the estimations we are using log transformations of the variables, we merged material and "other expenses" together, because the latter contains very diverse kind of expenses and is equal to zero for a non negligible number of utilities. We follow Garcia and Thomas (2001) in constructing a price variable for material and other expenses by dividing material and other expenses by the quantity of water delivered. This procedure seems acceptable, given the heterogeneity of the costs included in the material and other expenses categories and the lack of more pertinent data. All monetary amounts were deflated to 2003 constant Swiss francs using the producer's price index of the Swiss Federal Office of Statistics (currently, $1 \mathrm{CHF}=0.66 \mathrm{EURO}$ ).

To define capital stock one can either use a capacity measure or a cost measure applying the perpetual inventory technique as for example in Nelson (1989). Although the latter method is theoretically more appropriate, we cannot apply it due to the lack of appropriate data. Therefore, as in other studies (Nauges and van den Berg, 2008), we use the total network length as measure for the capital stock. Data on network length is collected each five years only (in our case in 2000 and 2005). For those utilities which have missing data in 2000 or in 2005 , we extrapolated it by assuming a linear investment path.

The first environmental factor is the proportion of pumped water over total water adduction. Ceteris paribus, a water utility which relies more on pumped water is expected to have higher costs. The percentage of water delivered to households accounts for the type of water customers. A relatively high proportion of households as customers should increase costs, compared to a water utility that dominantly supplies firms, which typically represent bigger customers. The load factor is the maximum amount of water distributed per customer per day divided by the mean amount of water supplied per customer per day. It is related to variation in water demand. Finally, network losses related to the quantity of water delivered are included into the analysis. As already mentioned, we use network length as the capital stock measure. But the networks of the water utilities differ widely in terms of age, material and maintenance. To capture part of these differences, we use network losses as a measure network quality, lower losses being an indicator of better infrastructure. We thus expect higher losses to imply higher variable costs. 
Table 1 - Descriptive statistics

\begin{tabular}{|c|c|c|c|c|c|c|}
\hline Variable & Measurement unit & Mean & Median & SD & Min & Max \\
\hline Variable cost & CHF (thousands) & 3087 & 1037 & 8449 & 112 & 65700 \\
\hline Output & $1000 \mathrm{~m}^{3} /$ year & 3152 & 1234 & 8188 & 94 & 70645 \\
\hline Labour price & $\begin{array}{l}\text { Thousands CHF } \\
\text { /worker/year }\end{array}$ & 96.37 & 91.55 & 37.68 & 40.12 & 251.62 \\
\hline Energy price & $\mathrm{CHF} / \mathrm{kWh} /$ year & 0.14 & 0.13 & 0.08 & 0.01 & 0.80 \\
\hline Material price & $\begin{array}{l}\mathrm{CHF} / 1000 \mathrm{~m}^{3} \text { water/ } \\
\text { year }\end{array}$ & 630.38 & 521.17 & 424.72 & 52.23 & 2438.42 \\
\hline Network & $\mathrm{Km}$ & 126.23 & 78.95 & 204.89 & 3.29 & 1630.12 \\
\hline Customers & Thousands & 20.78 & 9.38 & 54.06 & 0.73 & 440.32 \\
\hline Density & Customers/network unit & 0.13 & 0.12 & 0.08 & 0.02 & 1.13 \\
\hline Pumped water & $\begin{array}{l}\% \text { of total water } \\
\text { delivered }\end{array}$ & 0.72 & 0.86 & 0.33 & 0 & 1 \\
\hline Water to households & $\begin{array}{l}\% \text { of total water } \\
\text { delivered }\end{array}$ & 0.57 & 0.57 & 0.18 & 0 & 1 \\
\hline Load factor & - & 1.58 & 1.53 & 0.33 & 0.00 & 4.01 \\
\hline Network losses & $\begin{array}{l}\% \text { of total water } \\
\text { delivered }\end{array}$ & 0.11 & 0.11 & 0.07 & 0 & 0.43 \\
\hline
\end{tabular}

\section{Results and discussion}

The variable cost function (1) and the two cost share equations (2) are estimated using STATA 10.1 with an iterated SURE procedure, in order to account for the correlations between the disturbances of the different equations. The cross-equation constraints stemming from duality theory are imposed on the coefficients. As the system is estimated with iterated GLS, the results are invariant to which one of the cost shares is dropped from the system.

Table 2 contains the estimation results. We only report first order coefficients and do not include firm specific effects for space reasons. The estimated elasticity of cost with respect to output is positive and so are the estimated cost shares at over $99 \%$ of all observations. The estimated cost function is thus mostly monotonically increasing in output and in input prices. It should further be concave in input prices, meaning that the hessian matrix should be negative semi-definite. This property is however only respected for $41 \%$ of all data points, and thus some caution should be taken when interpreting the estimation results. The very high $\mathrm{R}^{2}$ of 0.98 highlights the good fit of the translog model.

We chose the median water utility as reference point for local approximation, thus all regressors of the system of equations are normalized by their sample medians. This allows for the direct interpretation of first order coefficients as cost elasticities evaluated at the median of all the variables. The coefficients of the output, of the price variables and of the number of customers served are all statistically significant and have the expected sign. As suggested by theory, the capital stock has a negative impact on variable cost, although the coefficient is not significant. The proportion of water that has to be pumped and the load factor possess the expected sign, but are not significant. Among the hedonic variables, only the network losses have a significant influence on variable costs. The higher the water losses, the higher the variable costs, showing that utilities can benefit from better quality infrastructure. Surprisingly, the coefficient of the proportion of households is negative, but not significant. 
Table 2 - Estimation results

\begin{tabular}{|c|c|c|c|c|}
\hline Variable & \multicolumn{4}{|c|}{ Translog cost function } \\
\hline Constant & $\alpha$ & -0.025 & & $(0.058)$ \\
\hline Output & $\beta_{\mathrm{y}}$ & 0.672 & $* * *$ & $(0.032)$ \\
\hline Labor price & $\beta_{\mathrm{pL}}$ & 0.321 & $* * *$ & $(0.005)$ \\
\hline Energy price & $\beta_{\mathrm{pE}}$ & 0.051 & $* * *$ & $(0.002)$ \\
\hline Network & $\beta_{\text {cap }}$ & -0.015 & & $(0.028)$ \\
\hline Time trend & $\beta_{\mathrm{t}}$ & 0.002 & & $(0.002)$ \\
\hline Customers & $\beta_{\text {cust }}$ & 0.248 & $* *$ & $(0.098)$ \\
\hline Pumped water & $\beta_{\text {part pu }}$ & 0.023 & & $(0.021)$ \\
\hline Water to households & $\beta_{\text {part house }}$ & -0.016 & & $(0.016)$ \\
\hline Load factor & $\beta_{\text {load }}$ & 0.002 & & $(0.010)$ \\
\hline Network losses & $\beta_{\text {part loss }}$ & 0.019 & $* * *$ & $(0.005)$ \\
\hline \multirow{2}{*}{$\ldots$} & & 340.00 & & \\
\hline & $\mathrm{R}^{2}$ & 0.9831 & & \\
\hline
\end{tabular}

Notes: standard errors in brackets.

*** statistically significant at $1 \% ; * * 5 \%, * 10 \%$.

Table 3 reports the price elasticities and Morishima elasticities of substitution, at the median. Standard errors are computed with the Delta method. As expected, all own-price elasticities are negative and significant, thus implying that an increase in the price of a given input leads to a drop in its demand. For example, a $1 \%$ increase in labour price would result in a $0.12 \%$ decrease in labour demand. Since all the estimated Morishima elasticities are positive and significant, the inputs are substitutes.

Table 3 - Estimated price elasticities and Morishima elasticities of substitution

\begin{tabular}{|c|c|c|c|c|c|c|c|c|c|c|c|}
\hline & \multicolumn{6}{|c|}{ Price elasticities } & \multicolumn{5}{|c|}{ Morishima elasticities of substitution } \\
\hline & Labour & & Energy & & Materi & & Labour & Energy & & Materi & \\
\hline Labour & $\begin{array}{l}-0.12 \\
(0.02)\end{array}$ & $* * *$ & $\begin{array}{r}0.04 \\
(0.01)\end{array}$ & $* * *$ & $\begin{array}{r}0.08 \\
(0.01)\end{array}$ & $* * *$ & 0 & $\begin{array}{r}0.75 \\
(0.08)\end{array}$ & *** & $\begin{array}{r}0.16 \\
(0.01)\end{array}$ & $* * *$ \\
\hline Energy & & & $\begin{array}{l}-0.71 \\
(0.07)\end{array}$ & $* * *$ & $\begin{array}{r}0.47 \\
(0.05)\end{array}$ & $* * *$ & & 0 & & $\begin{array}{r}0.55 \\
(0.05)\end{array}$ & $* * *$ \\
\hline Material & & & & & $\begin{array}{l}-0.08 \\
(0.00)\end{array}$ & $* * *$ & & & & 0 & \\
\hline
\end{tabular}

Notes: standard errors in brackets.

$* * *$ significantly different from 1 at $1 \% ; * * 5 \%, * 10 \%$

Returns to production density estimated for each individual utility for every year included in the sample vary between 0.95 and 2.64, while returns to scale range from 0.93 to 1.27 . As could be expected, the returns are decreasing with utility size. Looking at the returns to scale, this suggests that small utilities could benefit from mergers. This is not very surprising as the Swiss water distribution market is highly segmented and there is a large number of very small utilities. On the other hand, the biggest distributors seem to have already exploited possible economies of scale and seem to display constant or decreasing returns.

In order to have a more accurate analysis, we estimate marginal costs, returns to production density, customer density and scale at the median of the entire sample and 
for different sub-groups of utilities (table 4). The sample has been separated into small, medium and large utilities according to output quantity, number of customers and customer density. Groups are constructed by separating the $10 \%$ smallest (small utilities) and 10\% largest (large utilities) from the other firms (medium utilities). The economies and marginal costs have then been calculated with the median regressor values for each of the groups. The Delta method was used to calculate the standard errors.

Table 4 - Estimated returns to production density, customer density and scale and marginal costs

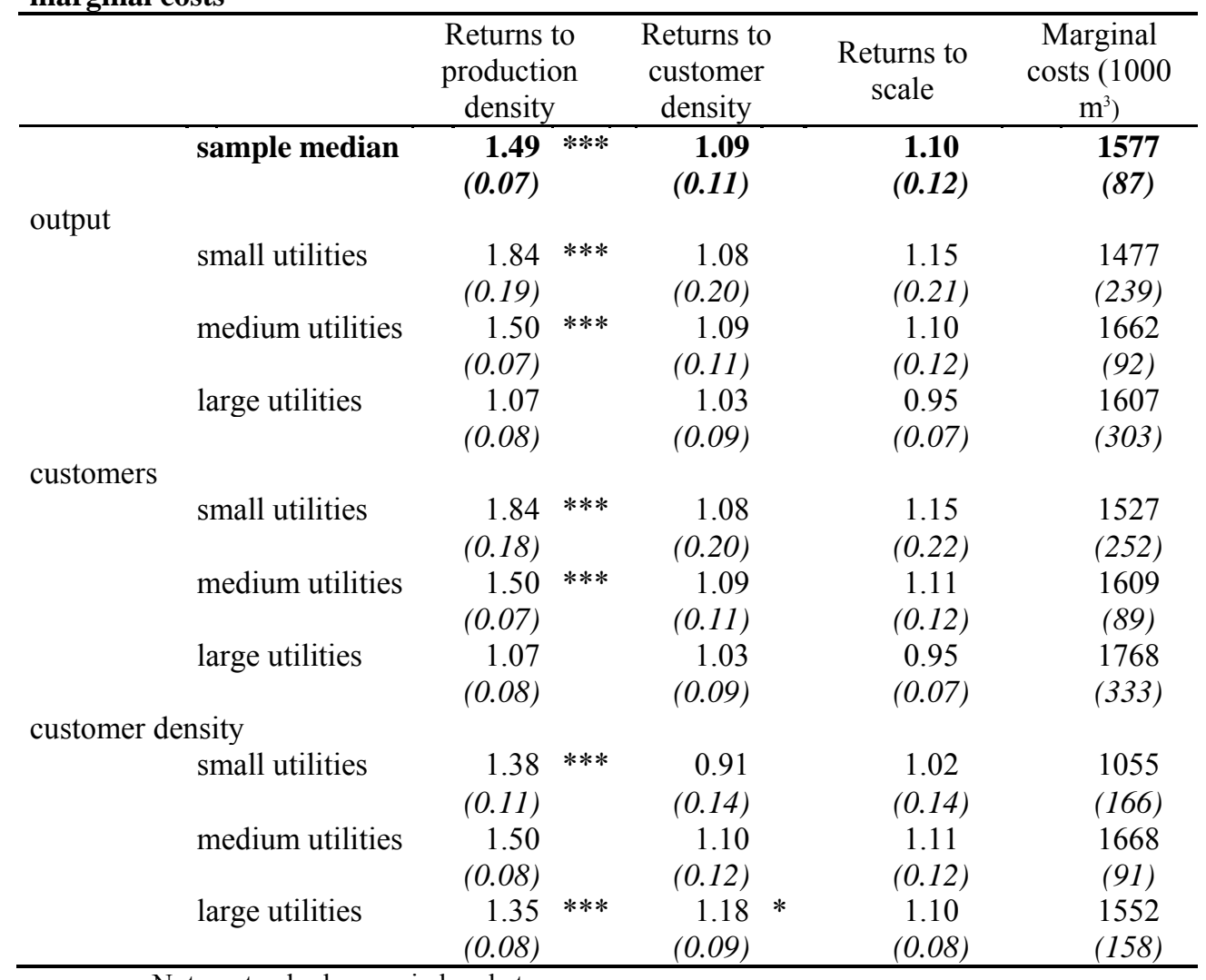

Notes: standard errors in brackets

$* * *$ significantly different from 1 at $1 \% ; * * 5 \%, * 10 \%$

Returns to production density are statistically significant in the output and customer sub-groups for small and medium sized utilities and seem to be decreasing with firm size, but still greater than one even for the largest utilities. We find economies of customer density in most sub-groups except for the utilities operating in the less densely populated areas, but none of the economies of customer density are significant except for the utilities operating in densely populated areas. This shows that a further increase in population density in urban areas would probably result in a decrease of average water distribution costs. Returns to scale are decreasing with size and seem to be increasing with density. None of the returns to scale is significantly different from 1 , consequently we cannot reject the hypothesis of constant returns to 
scale. But they are higher than 1 for small and medium size utilities (indicating potential economies of scale) while being smaller than 1 for large firms (hinting at diseconomies of scale). These results again indicate that mergers may be an attractive solution for small entities and points at an important problem: some of the small utilities might not be able to recover their costs with a marginal cost pricing policy because they experience economies of scale. Estimated marginal costs suggest decreasing returns to scale too, as they generally seem to be increasing with utility size. Marginal costs at the median of the sample are $1.57 \mathrm{CHF}$ per cubic meter of water. As expected in presence of economies of scale, the marginal costs are higher for bigger utilities. The information on the marginal cost could be used for tariff policies, remembering however its budgetary consequences in case of economies of scale.

\section{Conclusions}

In this paper, we have calculated the precise impact of a given factor on costs, assessed marginal costs, and detected potential economies of density and scale. Our results show in particular that in the Swiss water distribution sector there are moderate returns to production density (about 1.5 at the sample median), decreasing with the utility size. We find that returns to customer density and returns to scale are relatively low and statistically not significant, implying that we cannot reject constant returns to customer density and scale.

Our paper can be expanded in several directions. In particular, other empirical approaches can be used to estimate the cost function, whereby a particular attention should be given to random effects models. Moreover, as already mentioned, this paper is part of an on-going research project on the measurement of the technical efficiency of Swiss drinking water utilities. In our project, in addition to incorporating new data and additional variables, we are actually extending the approach presented in this paper in several directions. Firstly, we are comparing water distribution utilities by using stochastic cost frontiers (see Baranzini, Faust and Maradan, 2008). Secondly, we will also measure and discuss the performance of Swiss water utilities by applying a non parametric approach using data envelopment analysis (DEA).

\section{References}

Baranzini A. (1996). Structure des coûts des stations d'épuration en Suisse et gestion efficace des eaux usées. Swiss Journal of Economics and Statistics 132(4), pp. 515-538.

Baranzini, A. Faust, A.-K. \& Maradan, D. (2008). Water Supply: Costs and Performance of Water Utilities. Evidence from Switzerland. Paper presented the $13^{\text {th }}$ World Water Congress, International Water Resources Association (IWRA), Montpellier, September.

Berndt E.R. (1991). The practice of econometrics. Reading: Addison-Wesley Publ. Comp.

Bottasso A., Conti M. (2009). Scale economies, technology and technical change in the water industry: Evidence from the English water only sector. Regional Science and Urban Economics 39 (2), pp. 138-147.

Chambers R.G. (1988). Applied production analysis. Cambridge: Cambridge 
University Press.

Fabbri P., Fraquelli G. (2000). Costs and structure of technology in the Italian water industry. Empirica 27, pp. 65-82.

Farsi M., Filippini M. (2009). An analysis of cost efficiency in Swiss multi-utilities Energy Economics 31 (2), pp. 306-315.

Filippini M. (1994). Economies of scale and overcapitalization in the Swiss electric power distribution industry. Working paper, 9402. University of Zurich, Institute for empirical research in economics.

Garcia S., Thomas A. (2001). The structure of municipal water supply costs: application to a panel of French local communities. Journal of Productivity Analysis 16, pp. 5-29.

Greene W. (2002). Econometric Analysis. Prentice Hall, New York.

Kilchmann A. (2003). Distributeurs d'eau et analyse concurrentielle. Gwa 6, pp. 411418.

Luís-Manso P. (2005). Water Institutions and Management in Switzerland. Lausanne: Ecole Polytechnique Fédérale de Lausanne, College of Management of Technology, MIR-Report-2005-001.

Morishima M. (1967). A Few Suggestions on the Theory of Elasticity. Keiza Hyoron (Economic Review) 16 pp.144-50. (In Japanese).

Nauges C., van den Berg, C. (2008). Economies of density, scale and scope in the water supply and sewerage sector: a study of four developing and transition economies. Journal of Regulatory Economics 34, pp. 144-163.

Nelson R.A. (1989).On the measurement of capacity utilization. The Journal of Industrial Economics 37 (3), pp. 273-286.

Saal D., Parker D. (2001). The impact of privatization and regulation on the water and sewerage industry in England and Wales: a translog cost function model. Managerial and Decision Economics 21, pp. 253-268.

Swiss Gas and Water Industry Association - SGWA (several years): Résultats statistiques des distributeurs d'eau en Suisse. Zürich: SGWA.

Torres, M., Morrison Paul, C., 2006. Driving forces for consolidation or fragmentation in the US water utility industry: a cost function approach with endogenous output. Journal of Urban Economics 59, pp. 104-120. 
Cahiers de recherche du Centre de Recherche Appliquée en Gestion (CRAG) de la Haute Ecole de Gestion - Genève

\section{(C) 2010}

CRAG - Centre de Recherche Appliquée en Gestion

Haute école de gestion - Genève

Campus de Battelle, Bâtiment $\mathrm{F}$

7, route de Drize - 1227 Carouge - Suisse

$\triangle$ crag@hesge.ch

www.hesge.ch/heg/crag

(D) +41223881818

县 +41223881740

Tous les cahiers de recherche de la HEG sur RERO DOC :

http://doc.rero.ch/collection/HEGGE i.REPORT?ln=fr 